\title{
Edukasi Manajemen Latihan Pasien Diabetes Melitus Melalui Senam Kaki Diabetikum Pada Warga di Dusun Kanoman Bantul
}

\author{
Ike Wuri Winahyu Sari ${ }^{1}$, Novita Nirmalasari ${ }^{2}$, Rizqi Wahyu Hidayati ${ }^{3}$ \\ ${ }^{1,2,3}$ Keperawatan (S1), Fakultas Kesehatan, Universitas Jenderal Achmad Yani, Yogyakarta, \\ Indonesia \\ e-mail: ${ }^{1}$ ike.wuri@yahoo.com, ${ }^{2}$ novitanirmalasari@gmail.com, ${ }^{3}$ ririzpl@gmail.com
}

\begin{abstract}
ABSTRAK Senam kaki merupakan latihan yang dilakukan bagi penderita Diabetes Melitus (DM) atau bukan penderita untuk mencegah terjadinya luka dan membantu melancarkan peredaran darah bagian kaki. Perawat selain berperan dalam memberikan edukasi kesehatan juga dapat berperan dalam membimbing penderita DM untuk melakukan senam kaki sampai dengan penderita dapat melakukan senam kaki secara mandiri. Menurut hasil wawancara dengan ketua RT 2 Dusun Kanoman, di wilayah tersebut belum pernah diadakan penyuluhan tentang penyakit DM dan warga juga belum pernah diajarkan tentang senam kaki diabetikum. Kegiatan pengabdian masyarakat ini bertujuan untuk meningkatkan pengetahuan masyarakat tentang senam kaki diabetikum dan agar masyarakat mampu mendemonstrasikan gerakan senam kaki diabetikum secara mandiri. Kegiatan dilaksanakan di RT 1 dan 2 Dusun Kanoman, Pungkuran, Pleret, Bantul yang diawali dengan evaluasi awal pada masyarakat dengan diminta mempraktikkan gerakan senam kaki diabetikum dilanjutkan dengan penyuluhan dan demonstrasi. Selanjutnya evaluasi akhir dari penyuluhan dengan mendemonstrasikan senam kaki diabetikum secara mandiri dan diobservasi oleh penyuluh. Seluruh rangkaian kegiatan berlangsung dari Bulan Maret s.d. April 2021. Terdapat peningkatan keterampilan melakukan senam kaki DM dengan peningkatan rata-rata keterampilan sebesar 92\%. Dengan kegiatan ini peserta diharapkan dapat memberikan informasi yang telah diberikan oleh tim pengabdi kepada masyarakat lainnya di lingkungan tempat tinggal tentang penyakit DM dan senam kaki DM dan menerapkan hasil penyuluhan pada kehidupan sehari-hari sebagai langkah manajemen diri penyakit DM.
\end{abstract}

KATA KUNCI: Diabetes Melitus; Manajemen Latihan; Senam Kaki Diabetikum

ABSTRACT Diabetic leg exercise is an exercise for people with Diabetes Melitus (DM) or non-patients to prevent injuries and improve blood circulation in the legs. Nurses in addition to playing a role in providing health education, can also play a role in guiding people with DM to do leg exercises so that patients can do the exercises independently. According to the results of an interview with the head of RT 2 Dusun Kanoman, in this area there has never been any health eduaction about DM disease and the residents have never been taught about diabetic foot exercises. This community service activity aims to increase knowledge about diabetic leg exercises and so that people are able to demonstrate diabetic leg exercise independently. This activity begins with an initial evaluation of the community with participants being asked to practice diabetic leg exercises, followed by health education and demonstrations. Furthermore, the final evaluation of the health education that has been given is by demonstrating the diabetic leg exercises independently and being observed by the assistant. There is an increase in the skill of doing diabetic leg exercises with an average increase of 92\%. With this activity, participants are expected to be able to provide information 
that has been provided by the community service team to other communities in their neighborhood about DM and diabetic leg exercises and apply the results of health education in daily life as a self-management step for DM.

KEYWORDS Diabetes Melitus; Diabetic Leg Exercises; Exercise Management.

\section{Pendahuluan}

Diabetes melitus (DM) merupakan suatu penyakit kronis yang terjadi ketika pankreas tidak mampu menghasilkan insulin yang cukup, atau terjadi ketika tubuh tidak bisa menggunakan insulin secara efektif [1]. Penyandang DM ada sebanyak 422 juta jiwa dengan prevalensi sebanyak 8,5\%. DM menyebabkan kematian sebanyak 3,7 juta jiwa. Prevalensi orang dengan DM menurut International Diabetes Federation (IDF), pada tahun 2017 Indonesia masuk ke dalam peringkat 6 di dunia dengan jumlah pasien DM sebanyak 10,3 juta jiwa dan diprediksi akan mengalami peningkatan menjadi 16,2 juta jiwa pada tahun 2040 [2]. Berdasarkan data dari Riskesdas 2013-2018, prevalensi penyandang DM di Indonesia mengalami peningkatan dari 6,9\% menjadi 8,5\%, sementara itu secara nasional provinsi Daerah Istimewa Yogyakarta (DIY) masuk ke dalam urutan tiga besar pada penyandang DM [2].

Penyandang DM perlu mengontrol kadar gula darah dalam tubuh dan melakukan tindakan preventif seperti mengubah gaya hidup agar terhindar dari komplikasi [3]. Tindakan yang dapat digunakan untuk mencegah timbulnya komplikasi yaitu melalui edukasi, terapi gizi medis, latihan jasmani, dan terapi farmakologis. Untuk penyakit DM telah dikenal ada tiga penatalaksanaan yaitu mengatur pola makan, olahraga, dan obat-obatan.

Penatalaksanaan DM sebaiknya menggunakan olahraga dan disertai pengaturan pola makan [4]. Tujuan latihan adalah untuk meningkatkan kesegaran jasmani atau nilai aerobik optimal. Latihan sangat penting dalam penatalaksanaan DM karena dapat menurunkan kadar glukosa darah dan mengurangi faktor risiko kardiovaskuler. Latihan akan menurunkan kadar glukosa darah dengan meningkatkan pengambilan glukosa oleh otot dan memperbaiki pemakaian insulin [3].

Senam kaki merupakan latihan yang dilakukan bagi penderita DM atau bukan penderita untuk mencegah terjadinya luka dan membantu melancarkan peredaran darah bagian kaki [5]. Perawat sebagai salah satu tim kesehatan, selain berperan dalam memberikan edukasi kesehatan juga dapat berperan dalam membimbing penderita DM untuk melakukan senam kaki sampai dengan penderita dapat melakukan senam kaki secara mandiri.

Wilayah RT 1 dan 2 Dusun Kanoman, Pleret, Bantul merupakan salah satu desa binaan Universitas Jenderal Achmad Yani Yogyakarta yang dikelola oleh Himpunan Mahasiswa Ilmu Keperawatan (HIMIKA). Sasaran penyuluhan ini ditujukan pada warga baik yang menderita DM ataupun yang tidak. Menurut hasil wawancara dengan ketua RT 2 Dusun Kanoman, di wilayah tersebut belum pernah diadakan penyuluhan tentang penyakit DM dan warga juga belum pernah diajarkan tentang senam kaki diabetikum. Pertimbangan diadakannya kegiatan pengabdian masyarakat ini adalah sebagai bentuk edukasi bagi masyarakat supaya masyarakat memahami pentingnya latihan senam untuk mencegah terjadinya luka dan membantu melancarkan peredaran darah bagian kaki baik bagi penderita ataupun bukan penderita. Untuk lebih meningkatkan antusias warga dan terjadinya retensi pengetahuan dalam demonstrasi senam kaki diabetikum, kegiatan pengabdian kepada masyarakat ini dilengkapi dengan pendidikan kesehatan dan penayangan 
video sehingga dengan adanya tampilan audiovisual untuk senam kaki diabetikum membuat warga lebih tertarik.

Kegiatan pengabdian masyarakat ini bertujuan untuk meningkatkan pengetahuan masyarakat tentang senam kaki diabetikum dan agar masyarakat mampu mendemonstrasikan gerakan senam kaki diabetikum secara mandiri.

\section{Metode}

Kegiatan berlangsung pada bulan Maret s.d. April 2021 bertempat di rumah Bapak RT 2 Dusun Kanoman, Pungkuran, Pleret, Bantul. Untuk kegiatan penyuluhan dilaksanakan tanggal 4 April 2021. Jumlah peserta yang hadir pada kegiatan ini adalah sebanyak 15 peserta karena pembatasan warga di masa Pandemi COVID-9 untuk setiap kegiatan di masyarakat. Proses kegiatan pengabdian tercantum pada Gambar 1.

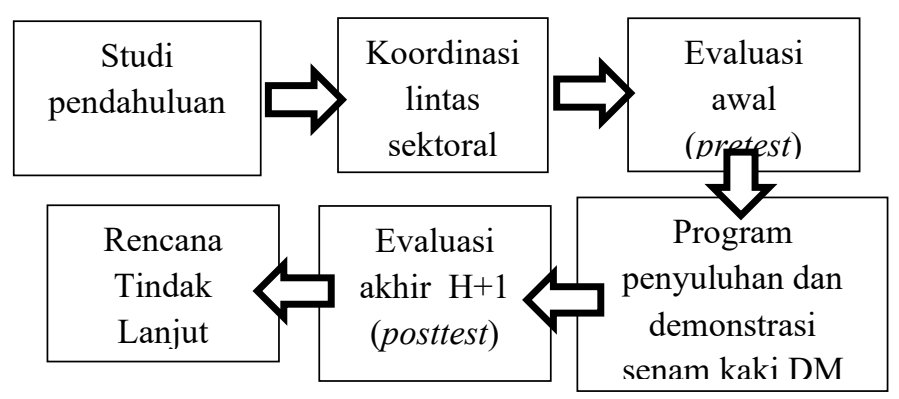

Gambar 1. Proses kegiatan pengabdian

Target capaian dari kegiatan ini adalah 100\% warga mengikuti kegiatan dari awal sampai akhir tanpa ada yang mengundurkan diri dan warga dapat mendemonstrasikan gerakan senam kaki diabetikum dengan benar 100\%. Program penyuluhan tentang edukasi senam kaki DM diawali dengan pemberian materi terlebih dahulu. Kemudian dilanjutkan dengan mengadakan pretest untuk demonstrasi senam kaki DM sebelum video ditayangkan. Setelah fasilitator mendokumentasikan hasil observasi terhadap gerakan setiap peserta, video senam kaki DM ditayangkan. Setelah sesi menonton video selesai, penyuluh memberikan kesempatan kepada peserta untuk bertanya tentang materi dan video yang telah ditayangkan. Kegiatan selanjutnya adalah evaluasi posttest untuk keterampilan senam kaki DM setiap peserta. Peserta diberikan video senam kaki DM untuk dapat disimak sewaktu-waktu di rumah. Evaluasi dilanjutkan di luar kegiatan penyuluhan sebanyak 1 kali evaluasi yang dilakukan oleh fasilitator, yaitu pada tanggal 11 April 2021. Setelah tahap evaluasi selesai dilaksanakan, tim pengabdi memberikan poster tentang edukasi kaki diabetikum.

\section{Hasil dan Pembahasan}

Selama kegiatan pengabdian kepada masyarakat berlangsung, peserta penyuluhan tampak sangat antusias menyimak video senam kaki DM dan memperhatikan dengan seksama untuk setiap gerakannya. Pada kegiatan pengabdian kepada masyarakat di RT 1 dan 2 Dusun Kanoman, Pungkuran, Pleret, Bantul ini didapatkan hasil yang tercantum pada Tabel 1.

Tabel 1 Karakteristik demografi orang dengan DM di RT 1 dan 2 Dusun Kanoman Bulan April $2021(\mathrm{n}=15)$ 


\begin{tabular}{cc}
\hline Karakteristik & Rata-rata \\
\hline Usia (tahun) & 54,46 \\
\hline Berat badan $(\mathrm{kg})$ & 61,67 \\
\hline Tinggi badan $(\mathrm{cm})$ & 157,73 \\
\hline Indeks massa Tubuh $(\mathrm{kg} / \mathrm{m} 2)$ & 24,79 \\
\hline Systole $(\mathrm{mmHg})$ & 131,33 \\
\hline Diastole $(\mathrm{mmHg})$ & 83,33 \\
\hline Gula Darah Sewaktu $(\mathrm{mg} / \mathrm{dL})$ & 120,53 \\
\hline
\end{tabular}

Rata-rata usia peserta penyuluhan adalah 54,46 tahun, rata-rata berat badan 61,67 kilogram, rata-rata tinggi badan 157,73 centimeter, rata-rata indeks massa tubuh (IMT) adalah 24,79 kg/m2; rata-rata tekanan darah systole 131,33 $\mathrm{mmHg}$; rata-rata tekanan darah diastole $83,33 \mathrm{mmHg}$; dan rata-rata gula darah sewaktu (GDS) adalah 120,53 mg/dL dengan GDS tertinggi $240 \mathrm{mg} / \mathrm{dL}$ dan GDS terendah adalah $49 \mathrm{mg} / \mathrm{dL}$.

Hasil selanjutnya adalah terkait karakteristik yang berkaitan dengan penyakit DM. Proporsi jenis kelamin peserta penyuluhan tercantum pada Gambar 2. Mayoritas peserta berjenis kelamin perempuan (73\%).

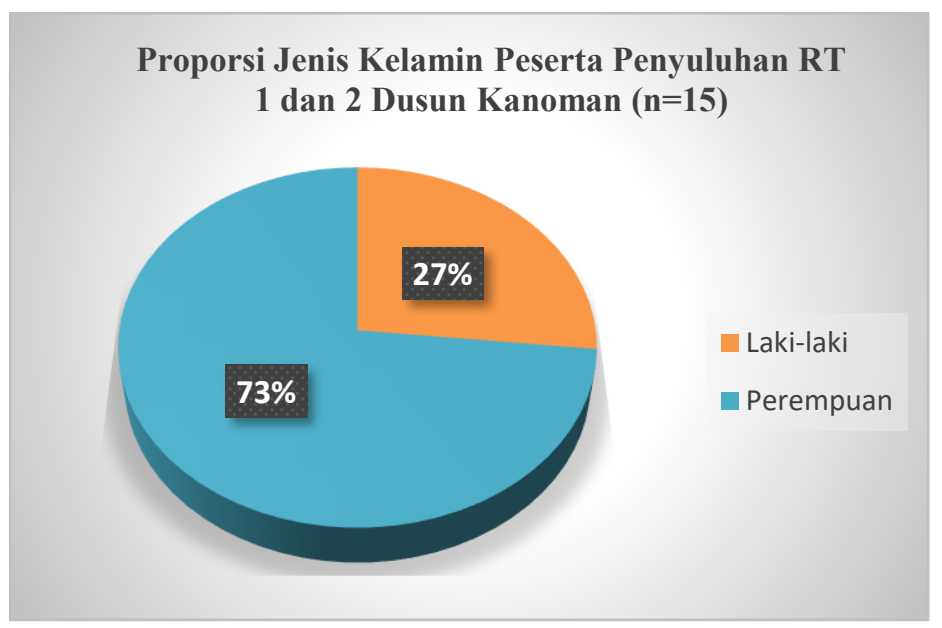

Gambar 2. Proporsi Jenis Kelamin Peserta Penyuluhan

Proporsi riwayat penyakit DM di keluarga peserta tercantum pada Gambar 3. Mayoritas peserta tidak memiliki riwayat penyakit DM di keluarganya (80\%).

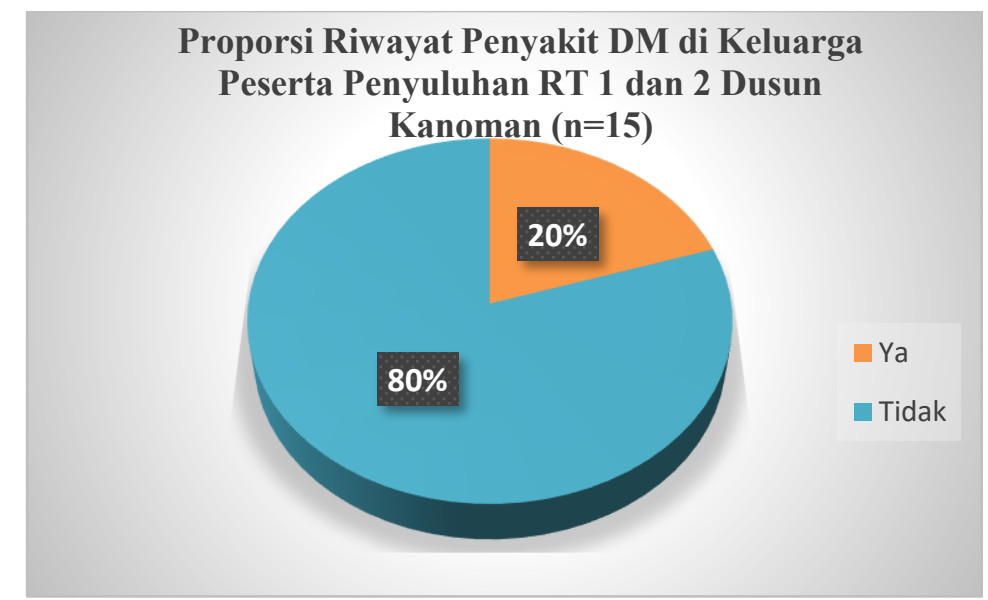

Gambar 3. Proporsi Riwayat Penyakit DM di Keluarga Peserta Penyuluhan

Proporsi riwayat penyakit DM pada peserta penyuluhan tercantum pada Gambar 4. Mayoritas peserta memiliki riwayat penyakit DM (73\%). 


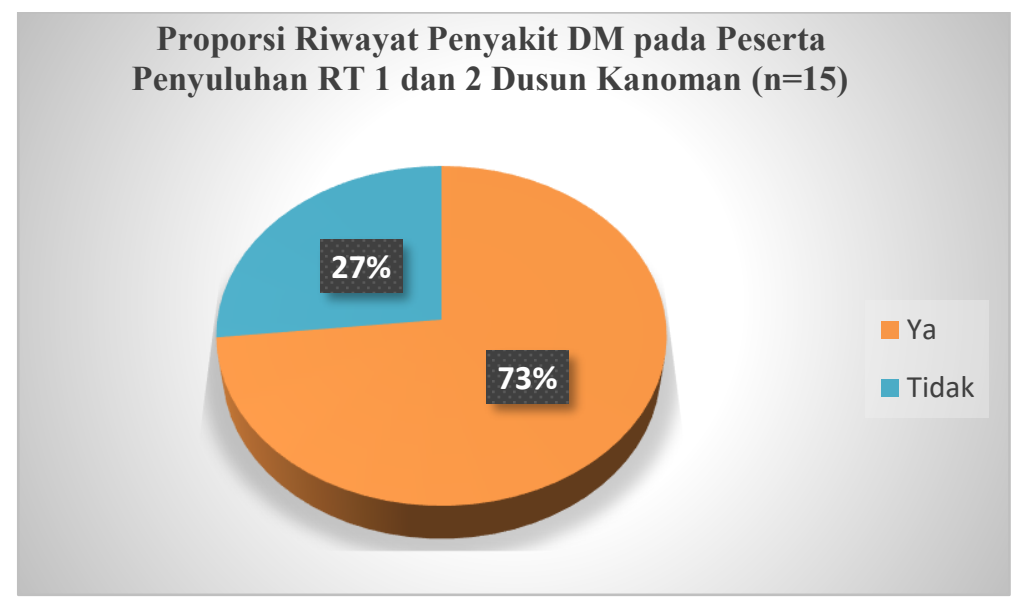

Gambar 4. Proporsi Riwayat Penyakit DM Peserta Penyuluhan

Proporsi adanya luka DM pada keluarga peserta penyuluhan tercantum pada Gambar 5. Mayoritas keluarga peserta tidak memiliki luka DM (93\%).

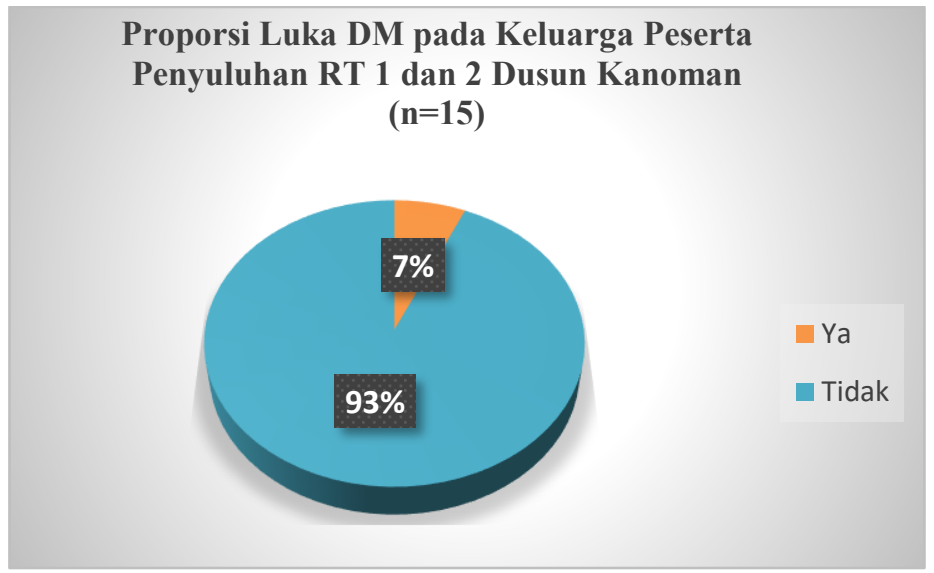

Gambar 5. Proporsi Luka DM pada Keluarga Peserta

Proporsi adanya luka DM pada peserta penyuluhan tercantum pada Gambar 6 . Mayoritas peserta tidak memiliki luka DM (80\%).

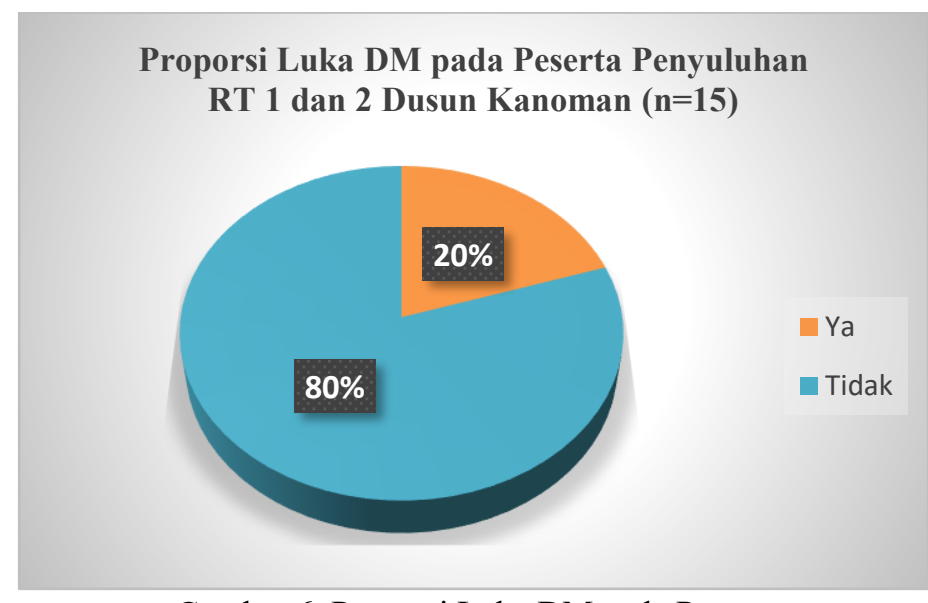

Gambar 6. Proporsi Luka DM pada Peserta

Proporsi kurangnya latihan fisik pada peserta penyuluhan tercantum pada Gambar 7. Mayoritas peserta tidak kurang latihan fisik (60\%). 


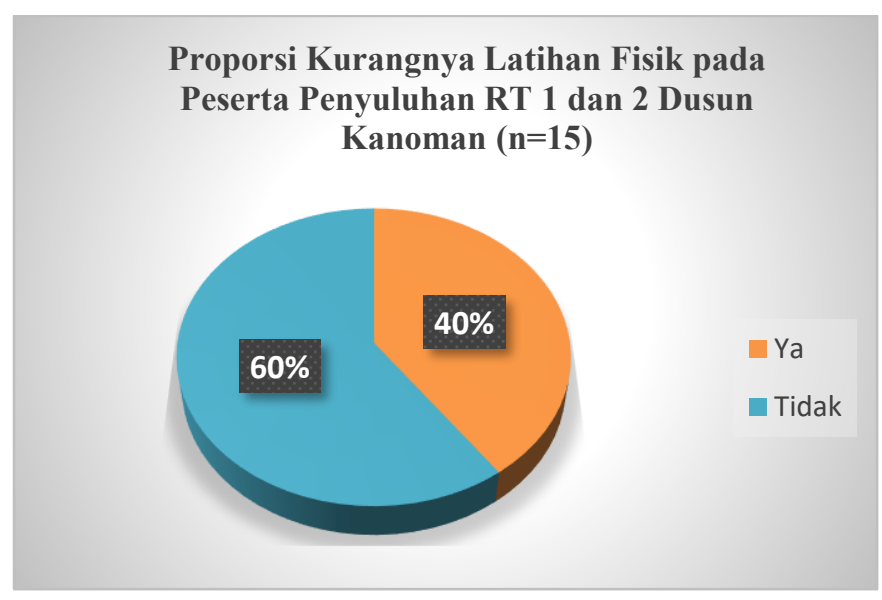

Gambar 7. Proporsi Kurangnya Latihan Fisik pada Peserta

Hasil selanjutnya adalah terkait dengan keterampilan senam kaki DM yang didemonstrasikan oleh peserta penyuluhan. Persentase keterampilan dihitung dengan cara membandingkan jumlah gerakan yang dilakukan oleh peserta dengan gerakan senam kaki DM sesuai yang diajarkan yaitu 11 gerakan. Keterampilan tersebut disajikan dalam persentase. Setelah menyaksikan video senam kaki DM terjadi rata-rata peningkatan keterampilan yang disajikan pada Gambar 8 berikut ini.

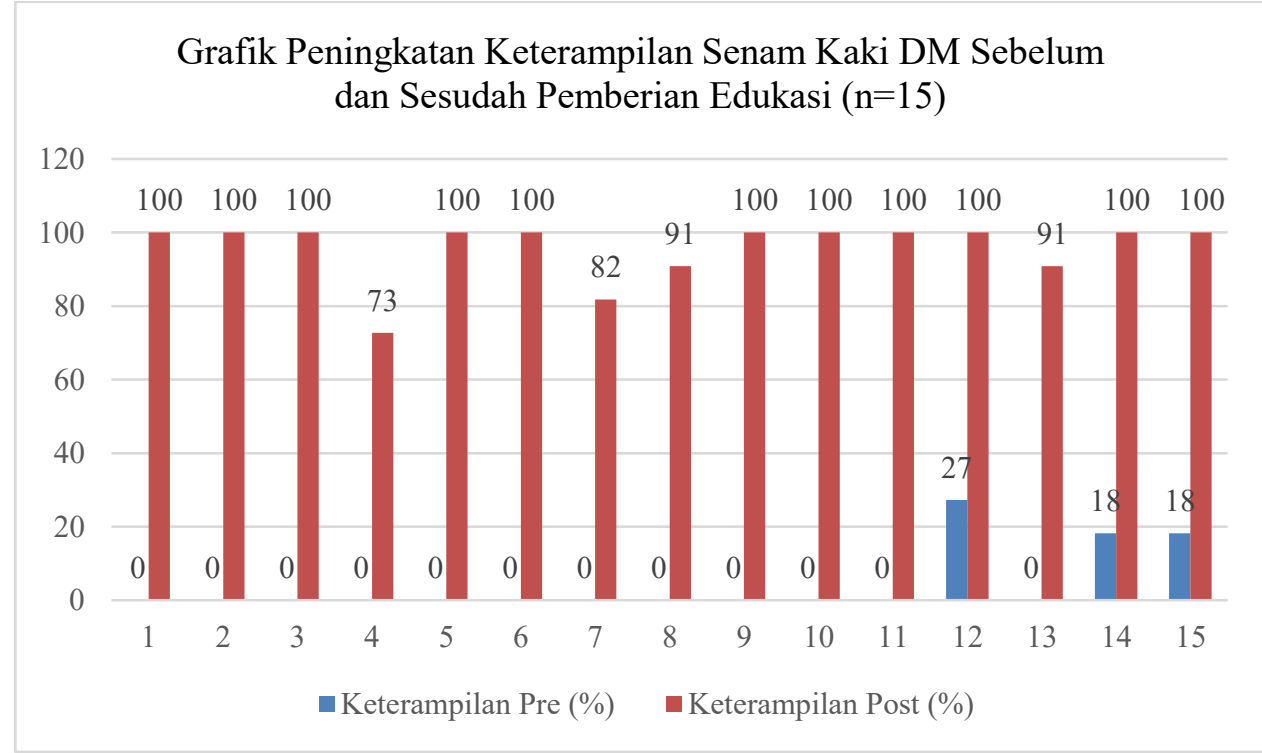

Gambar 8. Grafik Peningkatan keterampilan Senam Kaki DM pada Peserta Penyuluhan

Kegiatan pengabdian masyarakat berupa penyuluhan dan demonstrasi senam kaki diabetikum tercantum pada Gambar 9 dan Gambar 10.

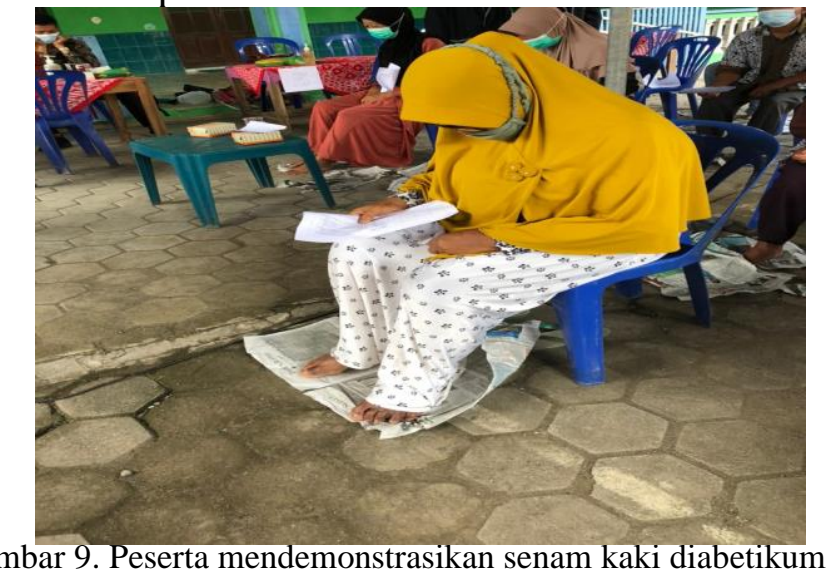




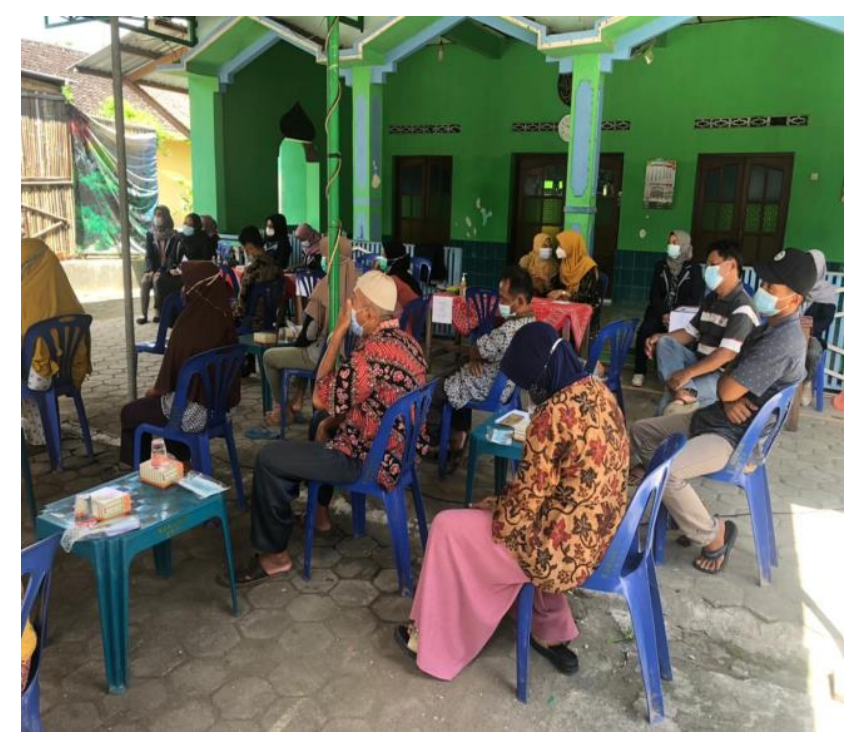

Gambar 10. Peserta menyimak materi penyuluhan

Pasien DM memiliki risiko mengalami gangguan sirkulasi pada bagian kaki, sehingga dapat menyebabkan ulkus diabetikum. Hal ini disebabkan oleh adanya penurunan sensasi dari nyeri perifer (neuropati) membuat pasien tidak sadar bahkan tidak merasa memiliki luka karena memang kehilangan sensasi [6].

Komplikasi pada kaki merupakan bagian yang sering dialami dan merupakan hal yang perlu menjadi perhatian perawat. Masalah kaki pada pasien diabetes tidak hanya pada gangguan persarafan namun juga pada pembuluh darah. Salah satu intervensi yang dapat dilakukan oleh perawat dalam mencegah terjadinya luka dengan mempertahankan kondisi vaskuler dan saraf perifer yaitu pasien diajarkan untuk melakukan senam kaki. Beberapa penelitian sudah mendapatkan hasil bahwa latihan aerobik dan latihan kekuatan yang melibatkan kaki menurunkan nyeri, gejala neuropati serta meningkatkan percabangan serabut saraf intraepidermal [7]. Senam kaki merupakan salah satu bentuk latihan fisik yang berfokus pada ekstremitas bawah yang dapat dilakukan oleh pasien diabetes untuk mencegah terjadinya penyakit arteri perifer.

Pengabdian kepada masyarakat ini dilakukan dengan penyuluhan dan dilanjutkan dengan demonstrasi senam kaki DM. Senam kaki DM termasuk dalam pilar latihan jasmani. Latihan jasmani pada senam kaki DM ini dilakukan dengan posisi duduk dan dalam keadaan rileks sehingga latihan senam kaki DM dapat dilakukan kapan saja disesuaikan dengan kondisi penderita DM, baik yang memiliki luka maupun yang tidak [8].

Kelelahan yang sering menjadi gejala bawaan dari penyakit DM membuat pasien DM memiliki aktivitas yang kurang sehingga membuat sirkulasi darah tidak lancar. Dengan adanya senam kaki DM ini maka sirkulasi darah pada penderita DM dapat menjadi lebih lancar dengan hasil berkurangnya tanda-tanda edema dan tidak ditemuinya ulkus diabetikum [9].

Kegiatan demonstrasi senam kaki DM pada pengabdian kepada masyarakat ini dilakukan dengan menayangkan video terlebih dahulu dengan sebelumnya warga diberikan pretest. Setelah menonton video kemudian dilakukan posttest terkait gerakan senam kaki DM. Video merupakan salah satu jenis alat edukasi audiovisual yang dapat menstimulasi indera penglihatan dan pendengaran. Audiovisual memiliki kelebihan menampilkan gerakan, memiliki efek tertentu sehingga memperkuat proses pembelajaran [10]. Menurut Piramida Edgar Gale, pendidikan kesehatan dapat dengan mudah tersampaikan melalui teknik mendengar dan 
melihat. Peserta pada penyuluhan ini melihat suatu objek dengan karakteristik suara dan gambar dengan indera penglihatan dan pendengaran dan selanjutnya stimulus tersebut diterima dan diolah oleh memori [11]. Hal tersebut sejalan dengan keberhasilan dari demonstrasi senam kaki DM pada kegiatan ini di mana mampu meningkatkan kemampuan gerakan dari peserta yaitu sebanyak $92 \%$.

Kegiatan pengabdian kepada masyarakat ini memiliki keunggulan berupa sajian audiovisual yang mampu menarik perhatian warga. Kegiatan ini juga mendapatkan dukungan penuh dari warga setempat sehingga kegiatan berjalan dengan lancar. Kelemahan kegiatan ini adalah kegiatan terlaksana pada masa pandemic sehingga tidak semua warga dapat mengikuti kegiatan penyuluhan, namun hal tersebut dapat diantisipasi dengan menempelkan poster edukasi di berbagai titik yang direkomendasikan sehingga warga yang tidak mengikuti kegiatan dapat memperoleh pengetahuan serupa.

\section{Kesimpulan}

Pada kegiatan pengabdian kepada masyarakat ini $100 \%$ dari jumlah yang ditargetkan yaitu 15 warga mengikuti kegiatan dari awal sampai akhir dan terdapat peningkatan keterampilan melakukan senam kaki DM dengan peningkatan rata-rata keterampilan sebesar $92 \%$. Peserta diharapkan dapat memberikan informasi yang telah diberikan oleh tim pengabdi kepada masyarakat lainnya di lingkungan tempat tinggal tentang penyakit DM dan senam kaki DM dan menerapkan hasil penyuluhan pada kehidupan sehari-hari sebagai langkah manajemen diri penyakit DM. Kegiatan pengabdian kepada masyarakat selanjutnya dapat memberikan penyuluhan berupa manajemen diri pasien DM selain manajemen latihan, misalnya berupa diet yang disertai contoh makanan dan berupa terapi herbal sesuai evidence based nursing atau rekomendasi dokter atau ahli gizi.

\section{Ucapan terima kasih}

Penulis mengucapkan terima kasih kepada ketua RT 1 dan 2 Dusun Kanoman, Pungkuran, Pleret, Bantul yang telah memfasilitasi kegiatan ini, serta para warga yang antusias dalam kegiatan pengabdian masyarakat yang telah dilaksanakan. Terima kasih pula kepada Fakultas Kesehatan Universitas Jenderal Achmad Yani Yogyakarta atas dukungan pendanaan dalam pelaksanaan kegiatan pengabdian kepada masyarakat ini.

\section{Daftar pustaka}

[1] World Health Organization, Global Report on Diabetes. Isbn, 978, 6-86. Accessed

http://www.who.int/about/licensing/copyright form/index.html\%0Ahttp:// www.who.int/about/licensing/copyright form/index.html\%0Ahttps://apps. who.int/iris/handle/10665/204871\%0Ahttp:/www.who.int/about/licensing /,2016.

[2] Kementerian Kesehatan Republik Indonesia, Riset kesehatan dasar 2018, Jakarta: Balitbangkes, 2018.

[3] Brunner \& Suddarth, Buku Ajar Keperawatan Medikal Bedah Edisi 8 Volume 2, Jakarta: EGC, 2013.

[4] Suryanto, Peran olahraga senam diabetes mellitus Indonesia bagi penderita diabetes mellitus, Pendidikan kesehatan dan reakrasi FIK UNY, 2009.

[5] Soegondo S., Soewondo P., Subekti I et al, Penatalaksanaan Diabetes 
Melitus Terpadu, Jakarta: Balai Penerbit Fakultas Kedokteran Universitas Indonesia, 2009.

[6] Rebolledo FA, Escobedo J, Soto JMT, The pathogenesis of the diabetic ulcer: prevention and management. Global Perspective on Diabetic Foot Ulcerations, 2011.

[7] Kluding PM, Pasnoor M, Singh R, et al., The effect of exercise on neuropathic symptoms, nerve function, and cutaneous innervation in people with diabetic peripheral neuropathy, J Diabetes Complications, 26(5):424-429. 2012.

[8] Flora R, Hikayati, Purwanto S., Pelatihan senam kaki pada penderita diabetes mellitus dalam upaya pencegahan komplikasi diabetes pada kaki (diabetes foot), Jurnal Pengabdian Sriwijaya, Pp 7-15, 2014.

[9] Widiawati S, Maulani, Kalpataria W., Implementasi senam kaki diabetes pada penderita diabetes melitus di RSUD Raden Mattaher Jambi, Jurnal Pengabdian Harapan Ibu, 2(1): 6-14, 2020.

[10] Uno HI \& Lamatenggo N, Teknologi komunikasi dan informasi pembelajaran, Jakarta: Bumi Aksara, 2010.

[11] Nursalam \& Efendi F., Pendidikan dalam keperawatan, Jakarta: Salemba medika, 2008. 